\title{
Hybrid Method For Forecasting A Steel Mill's Sales
}

Bogdan Rebiasz, (E-mail: brebiasz@ zarz.agh.edu.pl), AGH University of Science and Technology, Poland

\begin{abstract}
This paper presents a proposal of long range steel mill's sales forecasting method. It can be also used in other sectors of steel industry, and (after minor modifications) in enterprises operating in a power industry, building materials industry, plastics industry etc. Heuristic methods are often used in long range forecasting. In the proposed method few parameters are predicted with fuzzy Delphi method. It results in the forecasts in form of fuzzy triangular numbers. Transformation of possibility distribution, generated by fuzzy number, into a probability distribution enables to integrate forecasts obtained from fuzzy Delphi method with those prepared with structural models and developmental trends models. A computer simulation is used to determine sales forecast's expected value and probability distribution. In case of structural models and developmental trends models a simulation with re-estimation has been used. The method presented in this paper is used to generate random numbers from a set determined by triangular fuzzy number.
\end{abstract}

\section{INTRODUCTION}

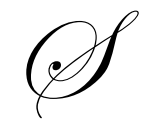

ales estimating is one of the most difficult problems in enterprise's development forecasting. In the same time it is the most important element of enterprise's development forecast, since sales' value determines enterprise's income. Long range sales forecasts, being a basis for investment decisions, are especially important. They often concern new product sales. Imperfection of anticipation of customers behaviours regarding new products has led to development of forecasting techniques, which utilize managers' and experts' opinions rather than market research.

Long range sales forecasting is especially important in capital-intensive industries with long equipment operation cycles, where false investment decisions are very costly and hard to correct. A classical example was a situation that emerged in British steel industry. In the 80s steel industry's capacity was two or three times higher than production. The reason was a lack of thorough analysis of steel products' market development prospects during preparation of steel industry development program [1].

It is emphasized in the literature, that pointwise forecast is more and more often insufficient for many models used in economic planning. In these models the risk accompanying each decision is usually taken into consideration. Determining forecast's probability distribution is thus necessary [2].

This paper presents a method of steel mill's long range sales forecasting. It integrates forecasting methods, which use structural models and developmental trends models, with heuristic methods. In the proposed method some parameters are predicted with fuzzy Delphi method. It results in the forecasts in form of fuzzy triangular numbers. Transformation of possibility distribution, generated by fuzzy number, into a probability distribution allows to integrate forecasts obtained from fuzzy Delphi method with those prepared with structural models and developmental trends models. A computer simulation is used to determine sale forecast's expected value and probability distribution. This method can be also used in other sectors of steel industry, and (after minor modifications) in enterprises operating in a power industry, building materials industry, plastics industry etc. 


\section{SALES FORECASTING METHODS FOR STEEL INDUSTRY}

Sales forecasting procedure in a steel company is usually a two-stage procedure and includes:

- $\quad$ steel products market development forecast,

- $\quad$ analysed enterprise's market share forecast.

Predicted sales value is a product of market value and enterprise's market share.

\section{Methods Of Steel Products Market Development Forecasting}

The most basic rate used in steel products consumption forecasting is intensity of steel use rate. The hypothesis regarding intensity of metal use was formulated for the first time by Malenbaum [3]. The intensity of metal use $\left(I U_{t}\right)$ is understood as number of consumed metals per GDP unit. Thus it can be determined for each year $t$ dividing a consumption of metal $M_{t}$ expressed in tonnes by $G D P$ value expressed in fixed prices with a formula:

$$
I U_{t}=\frac{M_{t}}{G D P_{t}}
$$

In accordance to Malenbaun the intensity of metal use changes depending on a relationship, which is in a form of a reversed letter $U$, if it is presented as a function of per-capita GDP. This theory was then developed by Tilton [4] and used for explaining the world's changes in consumption of metals. He introduced two key expressions serving to explain the consumption of metals in respective countries. The first one is $(P C I)$ - product composition of income. He understands it a relation of expenditures on a product $P$ to total income. It can be expressed with a formula:

$$
P C I=\frac{\text { expenditure on } P}{\text { total income }}
$$

The next value introduced by Tilton for models of the metal consumption there was a concept of material composition of product $(M P C)$. This value is measured with quantity of steel consumed at manufacture of a unit product. Thus it can be expressed with following formula:

$$
M C P_{t}=\frac{\text { quantity of steel for a product manufacture }}{\text { quantity of product }}
$$

Taking into account all the relations the steel consumption can be determined as:

$$
M_{t}=P C I_{t} \times M C P_{t} \times \text { total incom }
$$

Practically it is rather impossible to obtain detailed data which would help determining a structure of expenditures on respective products and also consumption of steel for the products. Thus to determine a value of determinant $P C I$ primarily there are taken shares of GDP produced in some selected sectors, deciding on steel consumption in relation to GDP total. However the determinant $M P C$ is calculated by dividing a quantity of steel consumed in a selected sector by a value of $G D P$ produced in the sector.

Evans [1] uses the intensity of use model at analyses of the intensity of steel use in Great Britain in the postwar. As characteristics of indicators $P C I$ he takes a share of the industry and building in creation of $G D P$ and a share of high technology industries to GDP produced by the total industry. Making an analysis of the intensity of steel use 
he assumes that determinant $M P C$ changes over a period of time and it depends on material-saving technologies applied in the industry and building and on substitution of steel with other materials.

Roberts [5] applies relations defined by Tilton for making an analysis and forecast of consumption of selected metals in the world. He analyses consumption of aluminium, copper, lead and zinc.

Crompton [6] uses the intensity of use model for making the analysis and forecast of steel consumption in Japan. The author makes an retrospective analysis of consumption in selected sectors which are: machinery, electrical machinery and equipment, transport equipment, other manufacturing, construction, and fabricated metal products. Steel consumption in each industry is decomposed into three fundamental determinants: the average quantity of steel used per unit of output, industry output relative to gross domestic product and gross domestic product. Forecast of these determinants are then used to construct steel consumption forecast. Such a way of forecast applied for the steel consumption compelled the author for making forecast values of determinants $M C P_{i t}$ and determinants $P C I_{i t}$ for each considered sector $i$. Determinants $M C P_{i t}$ are forecast using functions of trend, namely:

$$
M C P_{i t}=\phi_{i}+\varphi_{i} t
$$

where $\phi_{i}$, is a constant term, $\varphi_{i}$ measures the rate at which $M C P$ changes over a time in the $i$ th industry and $t$ is the time trend. Forecast for determinants $P C I_{i t}$ is made by use of a following model:

$$
P C I_{i t}=\alpha_{i}\left(\frac{1}{Y_{t}}\right)+\beta_{i}+\delta_{i}\left(\frac{\operatorname{dev} Y_{t}}{Y_{t}}\right)
$$

where $Y_{t}$ is a per-capita income and $\operatorname{dev} Y_{t}$ is the deviation of current per capita income from trend per capita income, such that:

$$
\operatorname{dev} Y_{t}=\text { current } Y_{t}-\text { trend } Y_{t}
$$

where trend $Y_{t}$ is measured using a simple linear trend in $Y_{t}$ over the sample and forecast period. A similar method is used by Roberts [7] in making forecasts of steel consumption in the USA.

Also other methods are applied for the steel forecast. Crompton [8] applies auto-regression models for predicting steel consumption in South-Eastern Asia. He makes forecasts for Singapore, Malaysia, Thailand, the Philippines and Indonesia.

Analogue method is another technique, used in steel products consumption forecasting. It is based on an assumption that intensity of steel use in the country, for which the forecast is being prepared, tends towards values characteristic for standard countries. Standards are selected by comparing GDP per capita and GDP creation structure of predicted object and potential standard objects. The objects, for which above-mentioned rates are closest to those of predicted object are chosen to be the standards. This selection is made for each prognostic year. Intensity of steel use rates in standard objects are taken as a forecast for predicted object.

\section{Market Share Forecast}

An assessment of enterprise's competitive position is needed to determine predicted market share. While realizing an investment project, an enterprise launches new or refined product. Company's competitive position usually changes then. Future changes of competitive position are decisive for sales forecasting. Different authors give different descriptions of basic characteristics, shaping a basis for competitive position assessment. However, there is a consensus of opinions that the most basic element is an assessment of degree of product offer adjustment to customers needs. 
There are methods that facilitate assessing the market share, for example conjoint measurement. Those procedures are utilized in marketing in order to measure consumer preferences with reference to products described by many characteristics (variables) and to estimate a market share of products with different levels of variables (characteristics) describing them [9]. Available literature presents also a form and methods of models estimation, which make market share conditional on application of chosen instruments, like price promotions, advertising in various media etc. These models are usually estimated for consumer products and concern short-term market share (e.g. weekly). Thus obtaining sufficiently long time series for models estimation is possible $[10,11]$. However, it is difficult to use such models in order to estimate steel products' market share in longer term (few years).

The assessment of future competitive position of the enterprise can be supported by formal methods. The range of those methods' use can vary. However, finally the market share is usually estimated by heuristic methods. The experts are managers, who express their opinions on enterprise's future market share.

\section{STEEL PRODUCTS MARKET FORECASTING}

While forecasting a development of steel products market the following three methods have been used:

- $\quad$ sector analysis method,

- $\quad$ econometric-analogue method,

- $\quad$ expert method.

\section{Sector Analysis Method}

While forecasting steel products' consumption in Poland the Crompton's model has been used [6]. Sectors of decisive meaning for steel products consumption have been chosen. The following sectors have been considered: metal containing products excluding machinery, mechanical machinery and equipment, electrical machinery and equipment, motor vehicles and other transportation, building, other sectors. Whole steel products consumption has been distributed among above-mentioned sectors. Official statistics of Polish Central Statistical Office and author's own studies have been utilized in order to make this division. While using official statistics of Central Statistical Office GDP created in each sector has been determined and also $M C P_{i t}$ and $P C I_{i t}$ ratios for above-mentioned sectors have been calculated (for the period 1992-2004). Next, on a basis of those data, equations describing changes of ration in the analysed period have been estimated. For $M C P_{i t}$ an equation no. 5 has been estimated. Character of observed trends indicated the usefulness of substituting a variable $\ln (t)$ or $\frac{1}{t}$ for a variable $t$, depending on the sector. In case of "other sectors" no significant time trends occurred for this ratio. Consumption in this group has been characterized by average value and standard deviation. For $P C I_{i t}$ equations no. 6 have been estimated. In case of $P C I_{t}$ for the sector: metal containing products excluding machinery, no statistically significant values of parameters have been obtained from equation no. 6. Thus a trend equation $P C I_{t}=\varphi+\rho\left(\frac{1}{t}\right)$ has been estimated for the period 1996-2004. Characteristic of obtained equations is presented in Tables 1 and 2. Forecast about apparent consumption of steel products has been calculated as per the following formula:

$$
M_{t}=\sum_{i=1}^{I} P C I_{t i} \times G D P_{t} \times M C P_{t, i}
$$


Table 1: Estimated Equations For The Material Composition Of Products ${ }^{1}$

\begin{tabular}{|c|c|c|c|}
\hline Industry & Equations & ADJ. $\mathbf{R}^{2}$ & $\mathbf{F}$ \\
\hline $\begin{array}{l}\text { Metal containing products } \\
\text { excluding machinery }\end{array}$ & $M C P_{t}=\underset{(14 . .8037)}{741.3491}+\underset{(3.0340)}{83.6666} \times \ln (t)$ & 0.4793 & 9.2052 \\
\hline $\begin{array}{l}\text { Mechanical machinery and } \\
\text { equipment }\end{array}$ & $M C P_{t}=\underset{(56, .970)}{418.1915}+\underset{(2, .274)}{47.8746} \times\left(\frac{1}{t}\right)$ & 0.3513 & 5.4170 \\
\hline $\begin{array}{l}\text { Electrical machinery and } \\
\text { equipment }\end{array}$ & $M C P_{t}=\underset{(197.5870)}{87.856}+\underset{(5.6362)}{6.9262 \times\left(\frac{1}{t}\right)}$ & 0.7606 & 31.7668 \\
\hline $\begin{array}{l}\text { Motor vehicles and other } \\
\text { transportation }\end{array}$ & $M C P_{t}=\underset{(12.9882)}{551.7748}+\underset{(3.2785)}{76.6956} \times \ln (t)$ & 0.5180 & 10.7487 \\
\hline Building $^{2}$ & $M C P_{t}=100.7265+43.5726 \times\left(\frac{1}{t}\right)$ & 0.6688 & 14.1357 \\
\hline
\end{tabular}

${ }^{1}$ values in parentheses show $t$ Student's distribution statistics

${ }^{2}$ for the equation estimation data for the years 1995-2004 were used

Table 2: Estimated Equations For The Product Composition Of Income ${ }^{1}$

\begin{tabular}{|c|c|c|c|}
\hline Industry & Equations & ADJ. $\mathbf{R}^{2}$ & $\mathbf{F}$ \\
\hline $\begin{array}{l}\text { Metal containing products } \\
\text { excluding machinery }{ }^{2}\end{array}$ & $P C I_{t}=\underset{(48.6899)}{0.01226}+\underset{(2.8020)}{0.00162 \times\left(\frac{1}{t}\right)}$ & 0.5669 & 7.8116 \\
\hline $\begin{array}{l}\text { Mechanical machinery and } \\
\text { equipment }\end{array}$ & $P C I_{t}=\underset{(55.57720)}{56.44398} \times\left(\frac{1}{Y_{t}}\right)$ & 0.8643 & 70.0400 \\
\hline $\begin{array}{l}\text { Electrical machinery and } \\
\text { equipment }\end{array}$ & $P C I_{t}=\underset{(4.1140)}{0.02136}-\underset{(2.6052)}{37.77781} \times\left(\frac{1}{Y_{t}}\right)-\underset{(3.4065)}{0.000635 \times t} \times t$ & 0.7394 & 12.7669 \\
\hline $\begin{array}{l}\text { Motor vehicles and other } \\
\text { transportation }\end{array}$ & $P C I_{t}=\underset{(47.4480)}{45.33347} \times\left(\frac{1}{Y_{t}}\right)$ & 0.8205 & 50.2847 \\
\hline Building & $P C I_{t}=\underset{(12.4195)}{0.14411}-\underset{(6.4661)}{310.59810} \times\left(\frac{1}{Y_{t}}\right)+\underset{(5.1004)}{0.04315} \times\left(\frac{1}{t}\right)$ & 0.8231 & 20.9382 \\
\hline
\end{tabular}

values in parentheses show $t$ Student's distribution statistics

${ }^{2}$ for estimation data for the years 1996-2004 were used

Table 3: Predicted GDP Growth Rates

\begin{tabular}{|c|c|c|c|c|c|c|c|c|c|c|}
\hline \multirow[t]{2}{*}{ Probability } & \multicolumn{10}{|c|}{ Years } \\
\hline & 2005 & 2006 & 2007 & 2008 & 2009 & 2010 & 2011 & 2012 & 2013 & 2014 \\
\hline 0,25 & 0,045 & 0,045 & 0,040 & 0,040 & 0,040 & 0,020 & 0,020 & 0,020 & 0,020 & 0,020 \\
\hline 0,50 & 0,050 & 0,050 & 0,045 & 0,045 & 0,045 & 0,035 & 0,035 & 0,035 & 0,035 & 0,035 \\
\hline 0,25 & 0,055 & 0,055 & 0,050 & 0,050 & 0,050 & 0,045 & 0,045 & 0,045 & 0,045 & 0,045 \\
\hline
\end{tabular}

A computer simulation has been used to determine forecast's expected value and probability distribution. In order to generate $P C I_{t}$ and $M C P_{t}$ forecasts a simulation with re-estimation has been used [12]. While preparing the forecast about apparent consumption of steel products predicted GDP growth rates (shown in Table 3) have been adopted.

Figure 1 presents the forecast about apparent consumption of steel products in the period 2005-2014, along with $95 \%$ confidence interval. As an example, this figure contains forecasts probability distribution for the years 2005 and 2014. 
Figure 1: Forecast About Apparent Steel Products Consumption In The Period 2005-2014, Prepared With The Use Of Sector Analysis Method
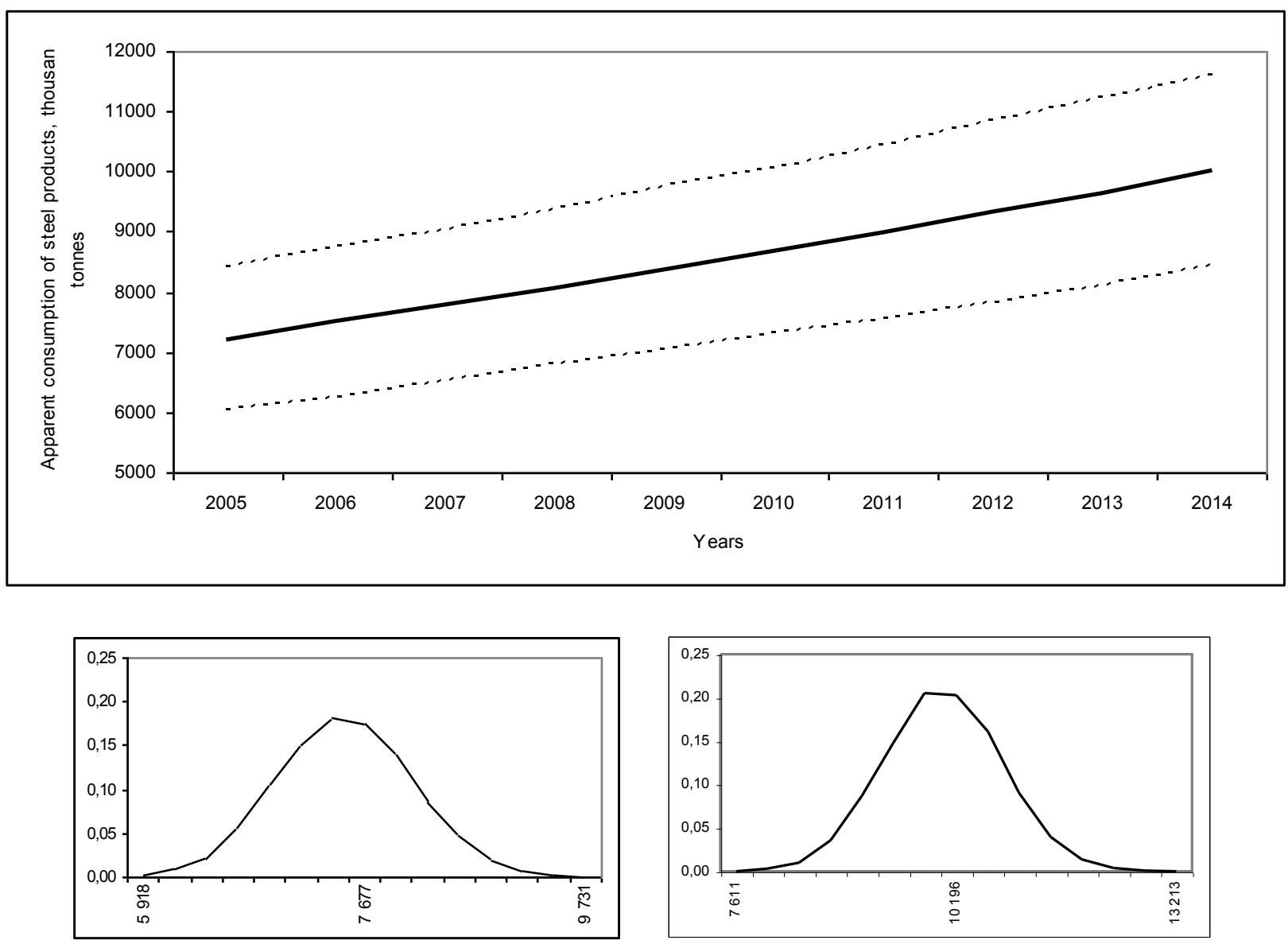

\section{Econometric-Analogue Method}

In this method data concerning other countries has been used to forecast intensity of steel use of Polish GDP. They have been used to estimate the following regression equation:

$$
\ln I U_{t}=a+b \ln G C_{t}+c \ln I B_{t}+d \ln I S_{t}+f \exp (0,02 t)
$$

where:

- $\quad I U_{t}-$ intensity of steel use in the year $t$,

- $G C_{t}-G D P$ per capita in the year $t$,

- $I B_{t}$ - industry's and construction sector's share in GDP creation in the year $t$,

- $I S_{\mathrm{t}}-$ steel-consuming sectors' share in GDP creation in the year $t$,

- $t$-time

- $\quad a, b, c, d, f-$ model's parameters 
The term $f \exp (0,02 t)$ of this expression is aimed at taking into account a trend towards decreasing the intensity of steel use in time, due to application of material-saving technologies in the industry and substitution of other materials for steel products. In order to prepare steel products consumption forecast for Poland, with the use of econometric-analogue method, statistical data concerning the following countries has been collected: France, USA, Japan, Spain, Italy, Belgium, Great Britain, Sweden, Denmark, Holland, Finland, Norway, Austria, Russia, Hungary, Slovakia, Czech Republic, Slovenia, Lithuania. The data concerning Japan, USA and Western Europe has covered the period 1960-2004, and in case of other countries - the period 1993-2004. Data concerning GDP for each country has been expressed in $U S D$, according to prices for the year $2000^{1}$. Coefficient 0,02 accompanying variable $t$ has been chosen experimentally. The equation has been estimated for different values of this parameter. The value, which minimised the residual sum of squares, has been chosen. On a basis of collected data a model of multiple regression has been built ${ }^{2}$ :

$$
\ln I U_{t}=\underset{(74,176329)}{5,378646}-\underset{(-7,145668)}{0,143636} \ln G C_{t}+\underset{(6,291667)}{0,262173 \ln I B_{t}}+\underset{(33,328215)}{0,713059} \ln I S_{t}-\underset{(-6,945986)}{0,087064} \exp (0,02 t)
$$

This equation has been used to forecast intensity of steel use of Polish GDP. Predicted intensity of steel use allows to determine a forecast about apparent consumption of steel, according to the following formula:

$$
M_{t}=I U_{t} \times G D P_{t}
$$

In order to prepare the forecast the GDP growth rates from Table 3 have been adopted. A computer simulation has been used to determine the forecasts about steel products apparent consumption's expected value and probability distribution. In order to generate forecasts a simulation with re-estimation has been used [12].

Figure 2 presents the forecast about apparent consumption of steel products in the period 2005-2014, along with $95 \%$ confidence interval. As an example, this figure contains forecasts' probability distribution for the years 2005 and 2014.

\section{Expert Method}

The key problem in preparing the forecast about apparent consumption of steel products is accurate predicting of changes in intensity of steel use in selected sectors. These changes take place under the influence of changes in manufacturing technologies, structural modifications in products and substituting other materials for steel. Intensity of these effects can be different in various periods. In an expert method changes in intensity of steel use are predicted with the use of fuzzy Delphi method. An algorithm for preparing forecasts in this method is shown below. Six experts have been chosen for each sector, in order to estimate predicted changes in intensity of steel use $\left(p_{i t}\right)$. The experts have been assessing the predicted changes in intensity of steel use in relation to the previous year. The obtained triangular fuzzy numbers, describing predicted changes in intensity of steel use, are presented in Table 4.

\footnotetext{
${ }^{1}$ Data drawn from appropriate annual volumes of the following publications: The Steel Market, International Statistical Yearbook, statistical yearbooks of separate countries.

${ }^{2}$ Values in parentheses show $t$ Student's distribution statistics
} 
Figure 2: Forecast About Apparent Consumption Of Steel Products

For The Period 2005-2014, Prepared With The Use Of Econometric-Analogue Method
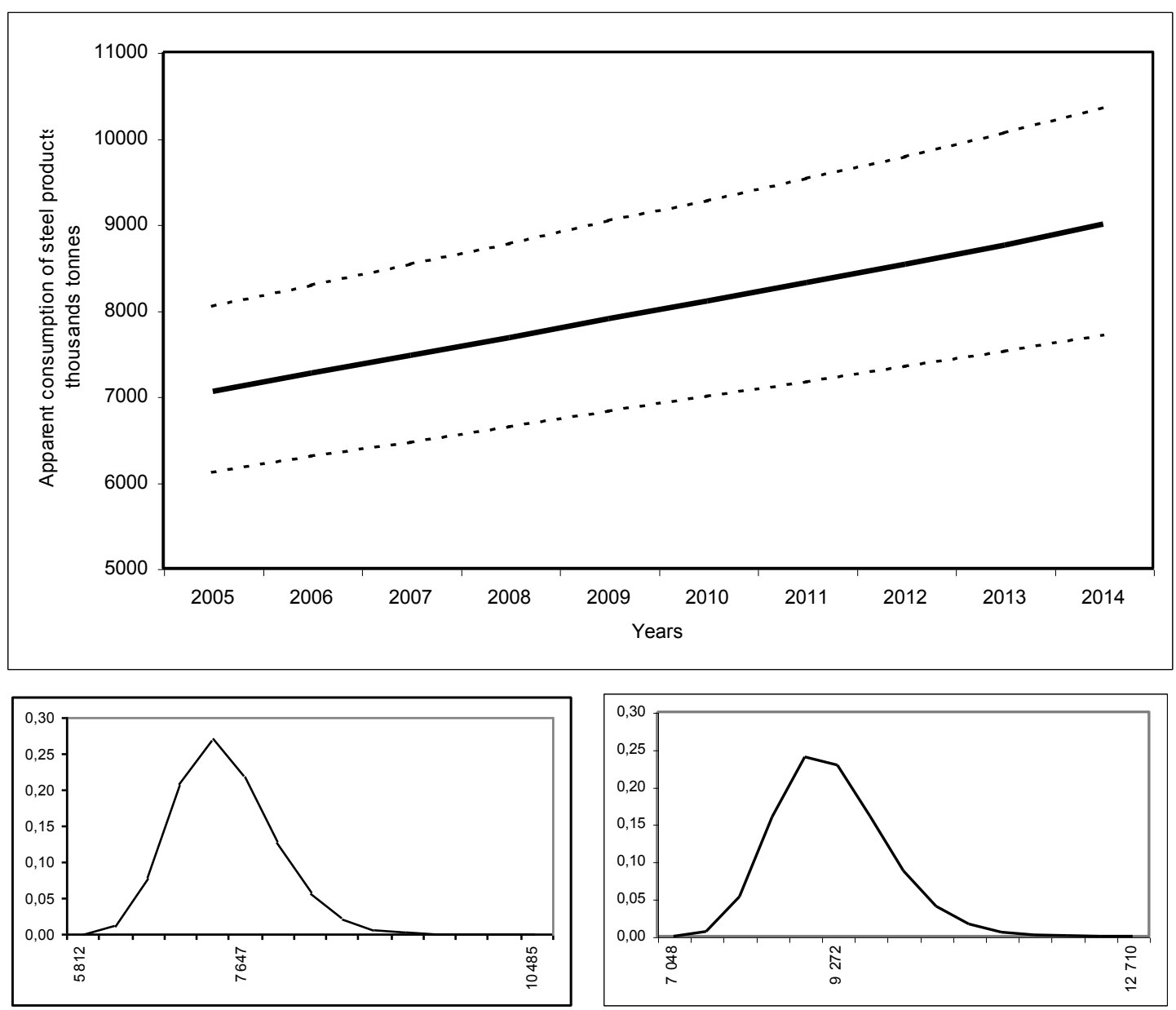

Table 4: Predicted Changes In Intensity Of Steel Use

In Analysed Sectors, Expressed By Triangular Fuzzy Numbers

\begin{tabular}{|c|c|c|c|c|c|}
\hline Year & $\begin{array}{c}\text { Metal containing } \\
\text { products excluding } \\
\text { machinery }\end{array}$ & $\begin{array}{c}\text { Mechanical machinery } \\
\text { and equipment }\end{array}$ & $\begin{array}{c}\text { Electrical machinery } \\
\text { and equipment }\end{array}$ & $\begin{array}{c}\text { Motor vehicles and } \\
\text { other transportation }\end{array}$ & Building \\
\hline 2005 & $(0.993 ; 1.000 ; 1.005)$ & $(0.950 ; 0.970 ; 0.990)$ & $(0.978 ; 0.985 ; 0.995)$ & $(1.000 ; 1.005 ; 1.010)$ & $(0.990 ; 1.000 ; 1.000)$ \\
\hline 2006 & $(0.993 ; 1.000 ; 1.005)$ & $(0.950 ; 0.970 ; 0.990)$ & $(0.978 ; 0.985 ; 0.995)$ & $(1.000 ; 1.005 ; 1.010)$ & $(0.990 ; 1.000 ; 1.000)$ \\
\hline 2007 & $(0.993 ; 1.000 ; 1.005)$ & $(0.960 ; 0.980 ; 0.990)$ & $(0.978 ; 0.985 ; 0.995)$ & $(0.995 ; 1.000 ; 1.000)$ & $(0.990 ; 1.000 ; 1.000)$ \\
\hline 2008 & $(0.990 ; 0.995 ; 1.000)$ & $(0.960 ; 0.980 ; 0.990)$ & $(0.978 ; 0.985 ; 0.995)$ & $(0.995 ; 1.000 ; 1.000)$ & $(0.990 ; 1.000 ; 1.000)$ \\
\hline 2009 & $(0.985 ; 0.990 ; 0.998)$ & $(0.960 ; 0.980 ; 0.990)$ & $(0.990 ; 0.995 ; 0.995)$ & $(0.980 ; 0.985 ; 0.993)$ & $(0.990 ; 1.000 ; 1.000)$ \\
\hline 2010 & $(0.985 ; 0.990 ; 0.998)$ & $(0.960 ; 0.980 ; 0.990)$ & $(0.990 ; 0.995 ; 0.995)$ & $(0.980 ; 0.985 ; 0.993)$ & $(0.990 ; 1.000 ; 1.000)$ \\
\hline 2011 & $(0.985 ; 0.990 ; 0.998)$ & $(0.960 ; 0.980 ; 0.990)$ & $(0.990 ; 0.995 ; 0.995)$ & $(0.980 ; 0.985 ; 0.993)$ & $(0.990 ; 1.000 ; 1.000)$ \\
\hline 2012 & $(0.985 ; 0.990 ; 0.998)$ & $(0.960 ; 0.980 ; 0.990)$ & $(0.990 ; 0.995 ; 0.995)$ & $(0.980 ; 0.985 ; 0.993)$ & $(0.990 ; 1.000 ; 1.000)$ \\
\hline 2013 & $(0.985 ; 0.990 ; 0.998)$ & $(0.960 ; 0.980 ; 0.990)$ & $(0.990 ; 0.995 ; 0.995)$ & $(0.980 ; 0.985 ; 0.993)$ & $(0.990 ; 1.000 ; 1.000)$ \\
\hline 2014 & $(0.985 ; 0.990 ; 0.998)$ & $(0.960 ; 0.980 ; 0.990)$ & $(0.990 ; 0.995 ; 0.995)$ & $(0.980 ; 0.985 ; 0.993)$ & $(0.990 ; 1.000 ; 1.000)$ \\
\hline
\end{tabular}


The above fuzzy numbers and regression equations, shown in Table 2, have been used to prepare the forecast of apparent consumption of steel products. The GDP growth rates from Table 3 have been adopted in this case too. The forecast has been calculated as per the following formula:

$M_{t}=\sum_{i=1}^{I} P C I_{t i} \times G D P_{t} \times M C P_{t-1, i} \times p_{t i}$

A computer simulation has been used to determine the forecast's expected value and probability distribution. In order to generate $P C I_{i t}$ forecasts a simulation with reestimation has been used. $M C P_{i t}$ ratios have been expressed as fuzzy number, since they are products of real number and triangular fuzzy number. The principles of rearranging possibility distribution, generated by fuzzy number, into probability distribution are presented below. A method of generating random numbers from a set defined by triangular fuzzy number is also presented. This method has been used in a computer simulation, in order to determine $M C P_{i t}$ ratios forecast. Figure 3 presents the forecast about apparent consumption of steel products in the period 2005-2014, along with 95\% confidence interval. As an example, this figure contains forecast's probability distribution for the years 2005 and 2014.

Figure 3: Forecast About Apparent Steel Products Consumption In The Period 2005-2014, Prepared With The Use Of Expert Method
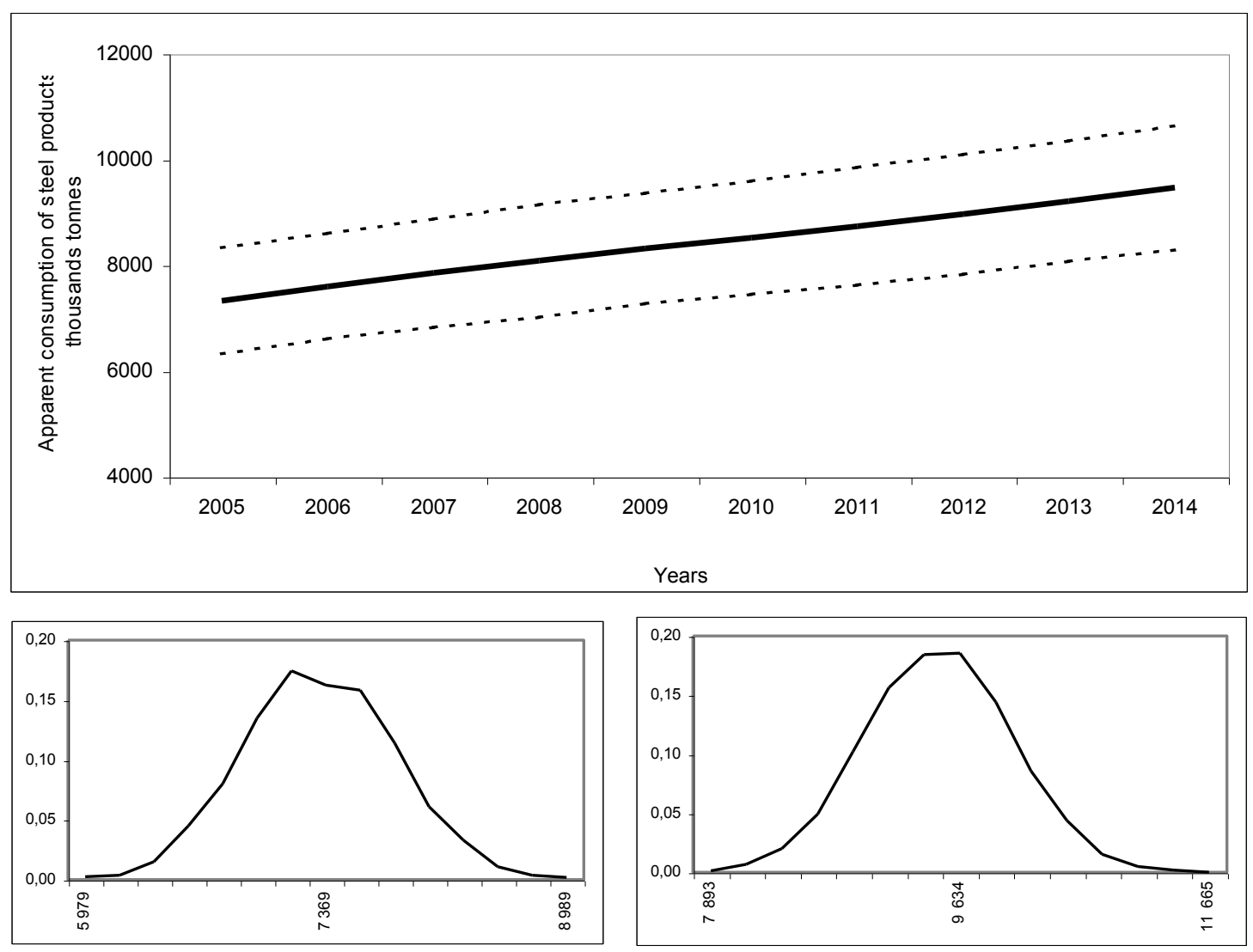


\section{Fuzzy Delphi Method}

Ishikawa et al. [13] were the precursors of using fuzzy sets theory in Delphi method. Subsequent authors have been using this method, adjusting it to their own needs $[14,15]$. In general it is possible to single out two types of fuzzy Delphi method. The first one allows to formulate fuzzy numbers describing the predicted occurrences on a basis of precise experts' answers [13, 14]. Modifications concern the form of fuzzy numbers' membership function. The second type allows to aggregate fuzzy experts' opinions into group, fuzzy, unanimous opinion [15]. In this paper the first method has been used. An algorithm of preparing the forecast with the use of fuzzy Delphi method is a modification of an algorithm presented by the method's authors: Dalkey and Helmer. If we denote the predicted index by $z_{i}$, an algorithm of fuzzy Delphi method can be described as follows. Each of $j$ experts determines predicted values of $z_{i}$. index, determining maximum $\left(\max z_{i j}\right)$ and minimum $\left(\min z_{i j}\right)$ predicted level. Researchers fuzzify obtained answers. They determine, one after the other:

- $\quad$ average maximum and minimum predicted values of index:

$$
\max _{i}=\frac{\sum_{j=1}^{n} \max z_{i j}}{n} \min \bar{z}_{i}=\frac{\sum_{j=1}^{n} \min z_{i j}}{n}
$$

where: $n$ - number of experts

- $\quad$ average values of assessment for each expert:

$$
a \bar{z}_{i j}=\frac{\min z_{i j}+\max z_{i j}}{2}
$$

- $\quad$ average values of experts' assessments:

$$
a v \bar{z}_{i}=\frac{\sum_{j=1}^{n} a v \bar{z}_{i j}}{n}
$$

The above values create triangular fuzzy numbers $T\left(\min \bar{z}_{i}, a \bar{z}_{i}, \max \bar{z}_{i}\right)$. The researchers calculate $\left({ }_{\min } \bar{z}_{i}-{ }_{\min } \bar{z}_{i j} ; a \bar{z}_{i}-a v \bar{z}_{i j} ; \max \bar{z}_{i}-{ }_{\max } \bar{z}_{i j}\right)$ for each expert $j$ and prepare a questionnaire once again, presenting the above values. Experts redetermine predicted values of ratios again. The researchers fuzzify obtained answers again. They calculate above-mentioned quantities for new experts' assessments. Next they calculate a distance between fuzzy number determined in current iteration and number determined in previous iteration. If the distance is lower than given, the research is over. Otherwise next questionnaire is prepared and the process continues until the distance between two subsequently determined fuzzy numbers is lower than given value. The distance between two triangular numbers $A\left(a_{1}, a_{2}, a_{3}\right)$ and $B\left(b_{1}, b_{2}, b_{3}\right)$ can be expressed by the following formula:

$$
\delta(A, B)=0,33 *\left(\sum_{i=1}^{3}\left(a_{i}-b_{i}\right)^{2}\right)^{0,5}
$$




\section{Rearranging Possibility Distribution Into Probability Distribution}

Relations between a probability theorem and a fuzzy sets theorem are one of the most controversial problems in the field of uncertainty modelling. An intermediate link between these concepts is possibility distributions [16-18]. Fuzzy set $G \in \mathcal{T}(\mathrm{X})$ (where $\mathcal{T}(\mathrm{X})$ is a class of all fuzzy subsets in an $X$ universe) generates a set function possibility measure $\Pi$. For each normal subset $A \subseteq X$ this measure is defined by the following formula:

$\Pi(A)=\sup \{G(x): x \in A\}$,

It is assumed that fuzzy set $G$ is a limitation of some variable $V$, adopting values in the universe $X$. It is also assumed, that the only information concerning this variable is a statement that , $V$ is $G$ ". Then the membership function of fuzzy set $G$ characterizes the variable $V$ and describes the possibility of adopting a value $x \in X$ by $V$, and thus induces the possibility distribution in universe $X$. Such defined variable $V$ is called fuzzy variable with possibility distribution:

$$
\pi(x)=G(x)
$$

Considerations with regard to rearranging possibility distributions into probability distributions were commenced by Zadeh [19]. The backgrounds for such rearrangements were formulated by Goodman and Nguyen [18] and Wang [20]. A concept is predominant in the literature that a possibility distribution facilitates a more adequate description of uncertainty than does a probability distribution. Hence, the process of rearrangement of a possibility distribution into a probability distribution is associated with issues concerning the additional information. This additional information is always slightly arbitrary. Formally a measure of possibility $\Pi$ described with an $X$ universe is equal to a family of probability measure $\mathscr{P}(\Pi)$ such that $\mathscr{P}(\Pi)=\{P, \forall A \subseteq X, P(A) \leq \Pi(A)\}$. Thus, the rearrangement boils down to defining $P(A)$ for each $A \subseteq X$ belonging to a range [N(A), $(\mathrm{A})]$, where $N(A)=1-\Pi(\bar{A})$ is a necessity measure $A$ and $\bar{A}$ is a complement of set $\bar{A}$. Dubois et al. [16] and Dubois and Prade [17] formulate consecutive conditions that are to be considered by a procedure of rearrangement of a possibility distribution into a probability distribution:

- $\quad \forall A, P(A) \leq \Pi(A)$ (a probability-possibility consistency)

- $\pi(x)>\pi\left(x^{\prime}\right) \Leftrightarrow p(x)>p\left(x^{\prime}\right)$ (a preference preservation)

- $\quad p$ contains as much uncertainty as possible (the least commitment).

A natural method for considering the latter condition is an assumption of an insufficient reason principle. This principle is focused on maintaining uncertainty of selection between possible realisations of a particular parameter. It means that if we know that $x$ belongs to a set $A$, then the maximum uncertainty with regard to $x$ can be described by a uniform probability distribution over $A$. For the given possibility distribution this principle is applied twice:

- $\quad$ for a selection of set $A_{\alpha}: \alpha$ is selected at random in (0,1] and it defines $A_{\alpha}\{x / \pi(x) \geq \alpha\}$

- $\quad$ for a selected value of $\alpha, x$ is selected at random within $A_{\alpha}$

This is a concept proposed by Yager [21]. In cases when $X$ is in a range [a,b] $\subseteq R$, and $\mu$ is the membership of an upper semi-continuous, unimodal, support bounded fuzzy number a function of probability density is formulated as [22]: 


$$
\forall x \in[a, b], p(x)=\int_{0}^{\mu(x)} \frac{d \alpha}{\left|A_{\alpha}\right|}
$$

where $\left|A_{\alpha}\right|$ is the width of the $\alpha$ - cut of $\mu$, i.e. if $A_{\alpha}=\left[m_{o}, M_{\alpha}\right]$ then $\left|A_{\alpha}\right|=M_{\alpha}-m_{\alpha}$.

Taking the above considerations into account, a procedure of generating random numbers from the set determined by triangular fuzzy number $A=(a, b, c)$ can be presented as follows. A random number $\alpha$ shall be drawn from a range $(0,1]$. A set $A_{\alpha}$ shall be defined as per formula:

$$
A_{\alpha}=\{x: a+\alpha(b-a) \leq x \leq c-\alpha(c-b)\}
$$

Then, assuming a uniform probability distribution for a set $A_{\alpha}$ a value is determined.

\section{AGGREGATED FORECAST ABOUT STEEL PRODUCTS MARKET}

Above-mentioned methods allow to prepare three forecasts about steel products' market development. The problem arises which method to choose, or how to aggregate those forecasts. Numerous publications [23-28] indicate that aggregating the forecasts is an effective method of reducing forecast error. In the analysed situation the available set of observations is not numerous. In order to estimate regression equations and developmental trends models only the data concerning the period 1992-2004 can be used. It is connected with social and economical changes that took place in Poland at the end of the 1980s and the beginning of the 1990s. This situation imposes limitations on a process of selecting the method of determining weights used to calculate aggregated forecast. In such case the following methods can be used: simple average method, out performance method, experts' judgement method [24, 25].

In the analysed case the experts' judgement method has been used. One should expect that errors in forecasts prepared with separate methods would demonstrate instability. In general one could expect that sector analysis method would give the most accurate forecasts in the nearest 2-3 years, expert method in the next 3-4 years and analogue method in other periods. Therefore it was assumed that weights for forecasts aggregation will be determined for subsequent two-years periods. The weights are presented in Table 5.

Table 5: Weights Used In Forecasts Aggregation

\begin{tabular}{|l|c|c|c|c|c|}
\hline Years & $\mathbf{2 0 0 5 - 2 0 0 6}$ & $\mathbf{2 0 0 7 - 2 0 0 8}$ & $\mathbf{2 0 0 9 - 2 0 1 0}$ & $\mathbf{2 0 1 1 - 2 0 1 2}$ & $\mathbf{2 0 1 3 - 2 0 1 4}$ \\
\hline Sector analysis method & 0.450 & 0.430 & 0.350 & 0.350 & 0.250 \\
\hline Econometric-analogue method & 0.150 & 0.170 & 0.250 & 0.300 & 0.500 \\
\hline Expert method & 0.400 & 0.400 & 0.400 & 0.350 & 0.250 \\
\hline
\end{tabular}

Figure 4 presents apparent consumption about steel products in the period 1992-2004 and an aggregated forecast of steel products consumption for the period 2005-2014, along with 95\% confidence interval. As an example, this figure contains forecasts probability distribution for the years 2005 and 2014. 
Figure 4: Apparent Consumption Of Steel Products In The Period 1992-2004 And An Aggregated Forecast About Steel Products Consumption For The Period 2005-2014
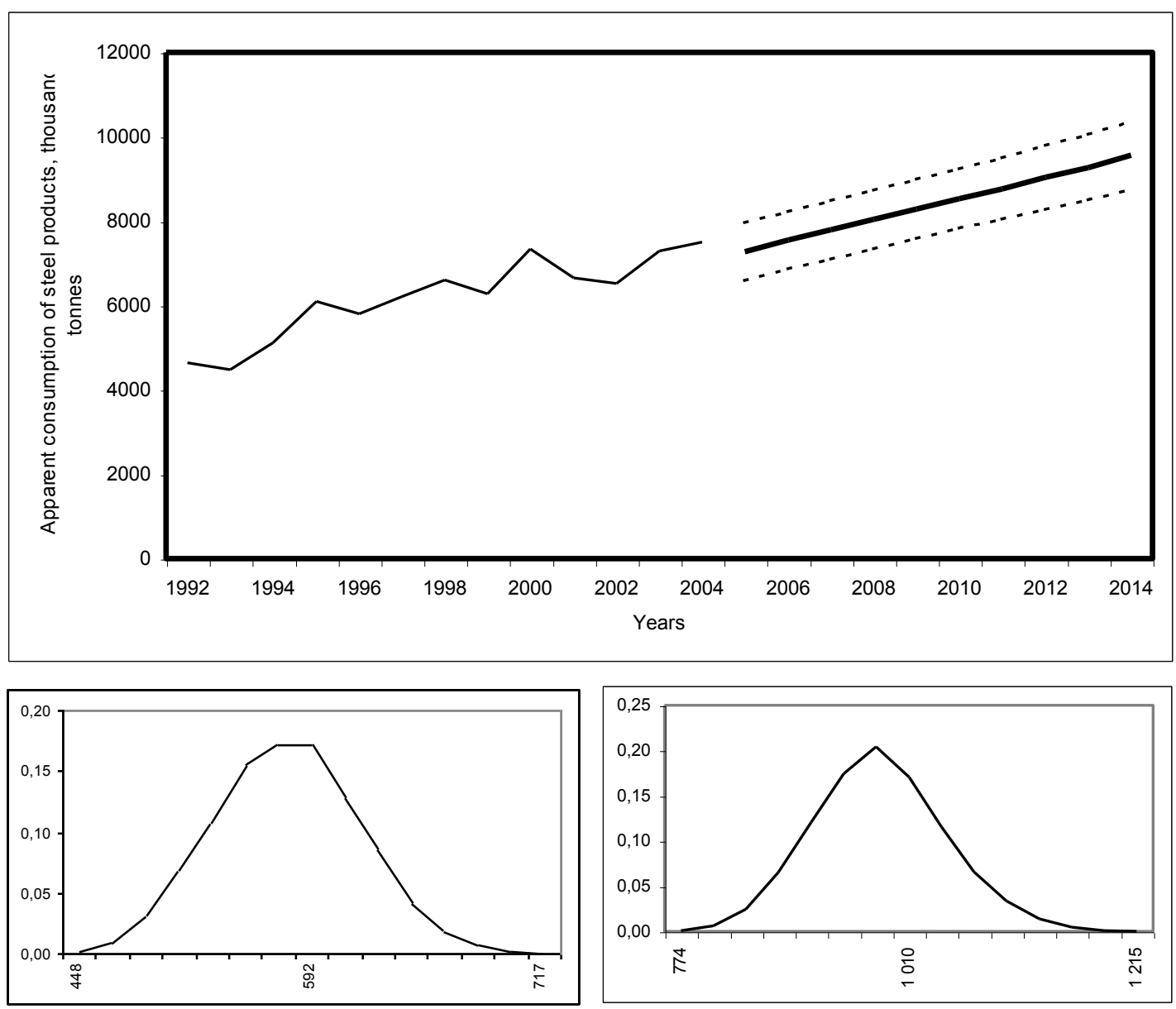

\section{SALES FORECAST}

Sales forecast has been prepared for a manufacturer of hot rolled sheets. While making the prediction there was a necessity of preparing a forecast about hot rolled sheet market, and then a forecast about analysed enterprise's market share. Size of a market for separate assortments of steel products is usually determined proportionally to apparent consumption of steel products. Thus predicted share of hot rolled sheets in the apparent consumption of steel products has been determined with fuzzy Delphi method. Similarly the share of analysed enterprise has been determined with the use of this method. Managers have been given the experts' roles. Ten experts have been chosen in each case. Since the manufacturer plans to modernize a hot rolling mill, a decrease of its market share has been predicted for the period of modernization work, and then abrupt increase of the share due to better quality of manufactured sheets has been forecasted. Fuzzy numbers presenting the share of hot rolled sheets in the apparent consumption of steel products and the enterprise's share in the hot rolled sheets market are shown in Table 6.

Figure 5 presents hot rolled sheets sales in the period 1992-2004 and sales forecast for the period 2005-2014. As an example, this figure contains forecasts probability distribution in the years 2005 and 2014. A computer simulation has been used to prepare the sales forecast. In order to generate predicted share of hot rolled sheets in the apparent consumption of steel products and predicted share of the enterprise in this market the above-mentioned method of generating random numbers from the set defined by triangular fuzzy number has been used. 
Table 6: Fuzzy Numbers Presenting The Share Of Hot Rolled Sheets In The Apparent Consumption Of Steel Products And The Enterprise's Share In The Market

\begin{tabular}{|c|c|c|}
\hline Years & Share of hot rolled sheets & Enterprise's share in the market \\
\hline 2005 & $(0.220 ; 0.237 ; 0.250)$ & $(0.380 ; 0.390 ; 0.400)$ \\
\hline 2006 & $(0.220 ; 0.235 ; 0.250)$ & $(0.275 ; 0.300 ; 0.325)$ \\
\hline 2007 & $(0.220 ; 0.235 ; 0.250)$ & $(0.360 ; 0.400 ; 0.440)$ \\
\hline 2008 & $(0.220 ; 0.235 ; 0.250)$ & $(0.420 ; 0.440 ; 0.460)$ \\
\hline 2009 & $(0.220 ; 0.235 ; 0.250)$ & $(0.420 ; 0.440 ; 0.460)$ \\
\hline 2010 & $(0.220 ; 0.235 ; 0.250)$ & $(0.410 ; 0.440 ; 0.460)$ \\
\hline 2011 & $(0.220 ; 0.235 ; 0.250)$ & $(0.410 ; 0.440 ; 0.470)$ \\
\hline 2012 & $(0.220 ; 0.235 ; 0.250)$ & $(0.400 ; 0.440 ; 0.480)$ \\
\hline 2013 & $(0.220 ; 0.235 ; 0.250)$ & $(0.400 ; 0.440 ; 0.480)$ \\
\hline 2014 & $(0.220 ; 0.235 ; 0.250)$ & \\
\hline
\end{tabular}

Figure 5: Hot rolled sheets sales in the period 1992-2004 and the forecast for the period 2005-2014.
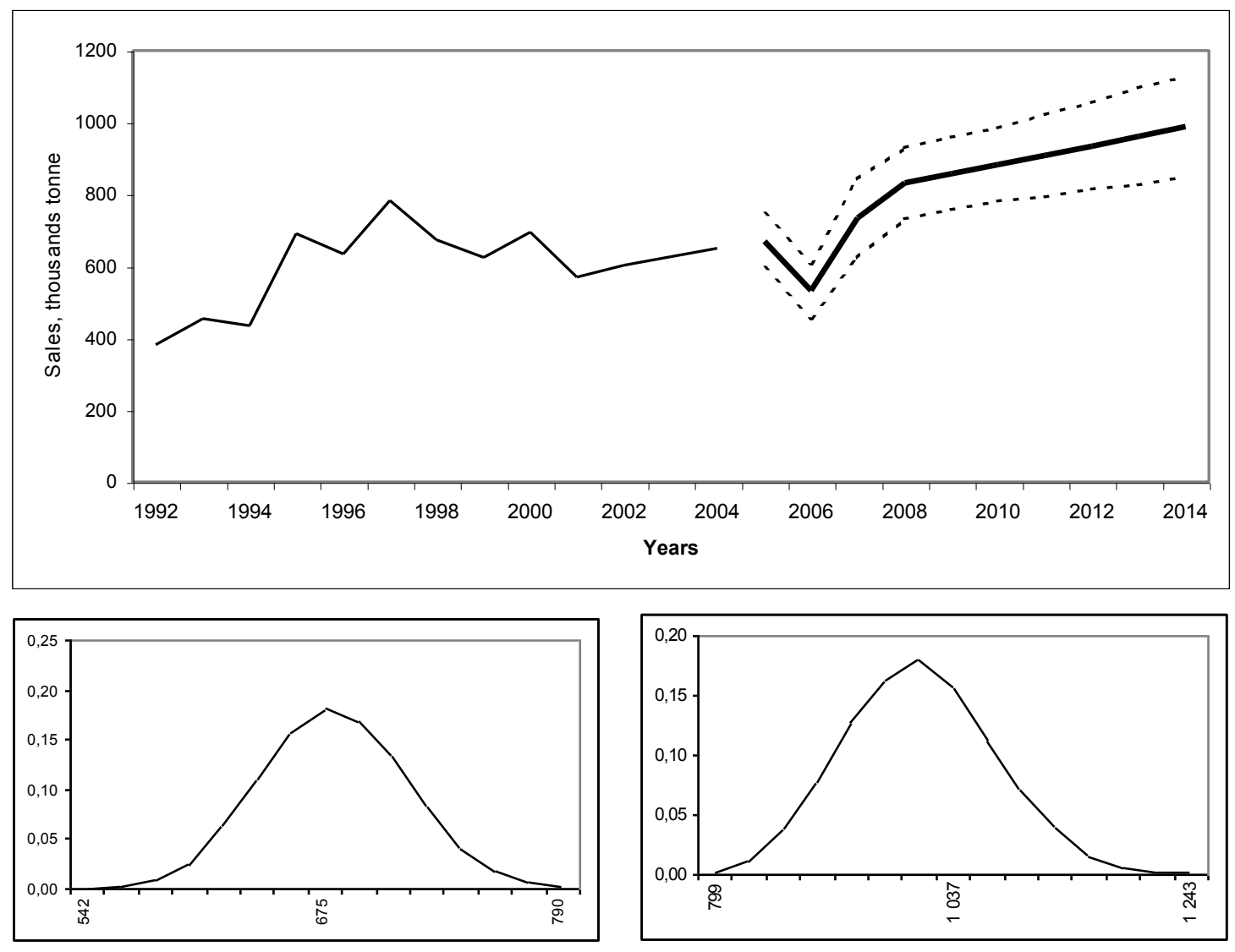

\section{CONCLUSION}

Sales estimating is one of the most difficult problems in enterprise's development forecasting. Long range sales forecasts are especially important in case of investment decisions making in the sectors with long equipment operation cycles. Steel industry is one of such sectors. Risk analysis is becoming more and more common in decision making. It demands not only determining a pointwise forecast, but also forecast's probability distribution. This paper 
presents a method of steel mill's long range sales forecasting. It can be also used in other sectors of steel industry, and (after minor modifications) in enterprises operating in a power industry, building materials industry, plastics industry etc. Heuristic methods are often used in long range forecasting. The above fuzzy Delphi method allows to obtain forecasts in form of fuzzy numbers. Rearranging possibility distribution, generated by fuzzy number, into probability distribution allows to integrate such forecasts with the forecasts obtained in structural models or developmental trends models. It also allows to determine forecast's probability distribution. In such case a computer simulation is used to determine probability distribution. Such method appeared to be effective in case of steel mill's sales forecasting. The most essential parameters of forecasting, such as intensity of steel use rates, hot rolled sheets share in the apparent consumption of steel products or enterprise's share in the market have been determined by the triangular fuzzy numbers.

\section{REFERENCES}

1. Abeele PV, Gijsbrechts E, and Vanhuele M. Specification and empirical evaluation of a claster-asymmetry market share model. International Journal of Research Marketing, 1990;7:223-247.

2. Agarwal MK and Green PE. Adaptive conjoint analysis versus self-explicated models: some empirical result. International Journal of Research in Marketing 1991;5:141-146.

3. Bianchi $\mathrm{C}$ and Calzorai G. Evaluating forecast uncertainty due to errors in estimated coefficients: empirical comparison of alternative methods. In: Chow G, C., Corsi P, editors. Evaluating the reliability of Macroeconomic models, New York; Wiley; 1982, p.281-304.

4. Chanas S and Nowakowski M. Single value simulation of fuzzy variables. Fuzzy Sets and Systems, 1988;2:43-57.

5. Clemen RT. Combining forecasts: A review and annotated bibliography. International Journal of Forecasting 1989;5:559-583.

6. Crompton P. Forecasting steel consumption in South - East Asia. Resources Policy 1999;2:111-123.

7. Crompton P. Future trends in Japanese steel consumption. Resources Policy 2000;26:103-114.

8. de Menezes LM., Bunn DW, and Taylor JW. Review of guidelines for the use of combined forecasts. European Journal of Operational Research 2000;210:190-204.

9. Dubois D and Prade H. Fuzzy sets and probability: Misunderstandings, bridges and gaps. Second IEEE International Conference on Fuzzy Systems. San Francisco, California, USA; 1993. p. 1059-1068.

10. Dubois D, Nguyen HT, and Prade H. Possibility theory, probability and fuzzy sets: misunderstandings, bridges and gaps. In: Dubois D, Prade H, editors. Fundamentals of Fuzzy Sets. Boston, Kluwer Academic Publisher; 2000; p. 343-348.

11. Evans M. Modelling steel demand in the UK. Ironmaking and Steelmaking 1996;1:19-23.

12. Fischer I. and Harvey N. Combining forecasts: What information do judges need to outperform the simple average. International Journal of Forecasting 1999;15:227-246.

13. Flores BE and White E M. Subjective vs. objective combining forecast: An experiment. Journal of Forecasting 1989;8:331-341.

14. Goodman IR and Nguyen HT. Uncertainty Models for Knowledge-Based Systems. Amsterdam: NorthHolland; 1985.

15. Hibon M. and Evgeniou T. To combine or not to combine: selecting among forecasts and their combinations. International Journal of Forecasting 2005;23:15-24.

16. His-Mei Hsu and Chen-Tung Chen. Aggregation of fuzzy opinions under group decision making. Fuzzy Sets and Systems 1996;79:279-285.

17. Ishikawa A, Amagasa M, Tomiquawa G, Tatsuta R, and Mieno H. The Max-Min Delphi method and fuzzy Delphi method via fuzzy integration. Fuzzy Set Systems 1993;55:241-253.

18. Klapper D. and Herwartz H. Forecasting market share using predicted values of competitive behavior: further empirical results. International Journal of Forecasting 2000;16:399:421.

19. Maines LA. An experimental examination of subjective forecast combination. International Journal of Forecasting 1996;12:223-233.

20. Malenbaum W. World demand for raw materials in 1985 and 2000. New York: McGrow-Hill; 1975.

21. Ping-Teng Chang. The fuzzy Delphi method via fuzzy statistics and membership function fitting and an application to the human resources. Fuzzy Sets and Systems 2000;3:511-520. 
22. $\quad$ Roberts, M.C. Metal use and the world economy. Resources Policy 1996;3:183-196.

23. Roberts, M.C. Predicting metal consumption: The case of US steel. Resources Policy 1990;1:56-73.

24. Taylor, J.W. and Bun D.W. Investigating improvements in the accuracy of prediction intervals for combinations of forecasts: A simulation study. International Journal of Forecasting 1999;15:325-339.

25. Tilton J.E. Beyond intensity of use. Materials and Society 1986;3:1-14.

26. Wang P.Z. From the fuzzy statistics to the falling random subsets. In: Wang editors. Advanced in fuzzy sets, Possibility Theory and Applications. New York: Plenum Press, USA; 1983, p.81-96.

27. Yager R.R. Level sets for membership evaluation of fuzzy subsets. In: Yager editors. Fuzzy Sets and Possibility Theory: Recent Developments. England: Pergamon Press, Oxford, 1982, p. 90-97.

28. Zadeh L.A. Fuzzy sets as a basis for a theory of possibility. Fuzzy Sets and Systems 1978;1:3-28.

\section{NOTES}

